\title{
A study of 25 years of publication outputs in the German academic profession
}

\author{
Christian Schneijderberg ${ }^{1,2}$ (D) $\cdot$ Nicolai Götze ${ }^{1}$ (D) Lars Müller $^{3}$ (D)
}

Received: 8 April 2020 / Accepted: 16 November 2021 / Published online: 11 January 2022

(C) The Author(s) 2022

\begin{abstract}
In the weak evaluation state of Germany, full professors are involved in the traditional social governance partnership between the state, and the self-governing higher education institutions (HEI) and disciplinary associations. Literature suggests that formal and informal governance could trigger changes in academics' publication behavior by valorizing certain publication outputs. In the article, secondary data from three surveys (1992, 2007 and 2018) is used for a multi-level study of the evolution of academics' publication behavior. We find a trend toward the "model" of natural science publication behavior across all disciplines. On the organizational level, we observe that a strong HEI research performance orientation is positively correlated with journal articles, peer-reviewed publications, and co-publications with international co-authors. HEI performance-based funding is only positively correlated with the share of peer-reviewed publications. At the level of individual disciplines, humanities and social sciences scholars adapt to the peer-reviewed journal publication paradigm of the natural sciences at the expense of book publications. Considering how the academic profession is organized around reputation and status, it seems plausible that the academic profession and its institutional oligarchy are key contexts for the slow but steady change of academics' publication behavior. The trend of changing academics' publication behavior is partly related to HEI valorization of performance and (to a lesser extent) to HEI performance based-funding schemes, which are set by the strong academic profession in the weak evaluation state of Germany.
\end{abstract}

Keywords Academic profession - Germany as weak evaluation state $\cdot$ Valorization of performance $\cdot$ Performance-based funding $\cdot$ Publication outputs

JEL Classification D73 $\cdot$ I23 $\cdot$ I28 $\cdot \mathrm{O} 35 \cdot \mathrm{O} 38$

Christian Schneijderberg

schneijderberg@incher.uni-kassel.de

1 International Centre for Higher Education Research, University of Kassel, Moenchebergstr. 17, 34109 Kassel, Germany

2 Institute for Sociology, RWTH Aachen University, Eilfschornsteinstraße 7, 52062 Aachen, Germany

3 Center for Teacher Education, Justus Liebig University of Gießen, Rathenaustraße 8, 35394 Giessen, Germany 
Mathematics Subject Classification $62 \mathrm{Hxx} \cdot 62 \mathrm{Axx} \cdot 91 \mathrm{Cxx}$

\section{Introduction}

The changing expressions of academic excellence (e.g., Bol et al., 2018; Bourdieu, 1975; Clark, 1983; Cole \& Cole, 1973; Merton, 1968) under managerial governance (e.g., Espeland \& Sauder, 2007, 2016; Gläser, 2019; Marginson \& Conside, 2000; Münch, 2014) are considered major international trends affecting the publication behavior of academics. For example, World University Rankings (e.g., Johnes, 2018; Kauppi, 2018; Selten et al., 2020) and the Journal Impact Factor (e.g., Karpik, 2011; Larivière \& Sugimoto, 2019) are considered major drivers of a metrification trend toward valorization of performance (VoP). The managerial transformation of qualities, such as creative ideas explained in academic publications, into quantities implies the construction of a "socio-calculative environment" (Vormbusch, 2012, p. 206; authors' translation), in which valorization ("to valorize, to give worth to"; Vatin, 2013, p. 33) creates a circular process including evaluation and valuation ("assessment of value"; Vatin, 2013, p. 31). Such valorization is based on the natural science publication "model" (Cole, 1983; Heintz \& Werron, 2011), which promotes publishing in refereed and listed English language journals, while monographs and contributions to edited books are considered less valuable. Accordingly, books are mostly not subject to indicator-led performance evaluation, which also affects publication cultures in humanities and the social sciences (e.g., Hammerfelt \& de Rijcke 2015, Mathies et al., 2020). This valorization of performance $(\mathrm{VoP})$ according to the natural sciences publication paradigm is executed top-down in "strong evaluation states" (Whitley, 2007, p. 9), such as Australia (e.g., Butler, 2003a, 2003b; Woelert \& McKenzie, 2018), the United Kingdom (e.g., Moed, 2008), South Korea (e.g., Choung \& Hwang, 2013; Shin \& Lee, 2015; Shin et al., 2009) and other East Asian countries (e.g., Lyu et al., 2017; Park et al., 2016).

In comparison to Australia, South Korea and the UK, Germany is a weak evaluation state (Gläser, 2019; Schimank, 2010). In the absence of federal jurisdiction, the higher education and science laws of the 16 federal states stress higher education institutions' (HEI) autonomy. HEI leadership and academic self-governance bodies (e.g., academic senate) are responsible for applying performance evaluations or not (Huber \& Hillebrandt, 2019). Accordingly, in the weak evaluation state Germany, the organizational level has to be considered as well as the natural science publication paradigm when studying possible changes in academics' publication behavior. The goal of this study is to empirically observe the changes in individual publication behavior of academics by answering two research questions (RQ):

RQ1: Can we observe a convergence of other disciplines to the natural science model of publication?

RQ2: Are HEIs' performance orientation and performance-based funding policies connected to changes in academics' publication behavior?

Using three surveys, we can study the changing publication behavior in the German academic profession by looking at publication outputs over the course of the last 25 years (1992-2007-2018). Using surveys allows us to consider multiple types of publications. Databases such as Web of Science would not be appropriate, as they do not comprehensively cover all humanities and social sciences publications, such as books, non-peerreviewed articles and non-English journals (Chi, 2015; Ossenblok et al., 2014). Therefore, 
our study can complete the picture especially with regard to humanities and social sciences in a non-native English language country (see Puuska, 2014 for limitations of surveys).

We proceed as follows: In "A literature-based description of VoP in GermanyA literature-based description of VoP in Germany" section, we present a brief overview of the German higher education and science system as a weak evaluation state. In 'Data' section, we describe the data that we use to answer the research questions. We use surveys conducted at three different points in time (1992, 2007 and 2018). Section “Methods” presents the methods, section "Results" the results, which are discussed and concluded in "Discussion of results and conclusions"' section.

\section{A literature-based description of VoP in Germany}

\section{Brief overview of the German higher education and science system}

In Germany, academics benefit from relatively strong protection against interference by the state in their research and teaching on the basis of the German constitution (Grundgesetz, article 5(3)1) and are granted a relatively strong position in higher education and science governance. In the social partnership (Sozialpartnerschaft) between the state and the academic profession (Stichweh, 1994; see also: McClelland, 1990; Schimank, 2005; Scott, 2005), the strong academic oligarchy ${ }^{1}$ in positions such as HEI leadership, academic senates, national academic bodies (e.g., German Rectors' Conference and German Science Council (Wissenschaftsrat)), etc. (Brennan, 2010; Pusser, 2008) influences law making and how the law is applied. For example, since 2005 the law on the so-called W-remuneration (Professorenbesoldungsreformgesetz) (Klenke, 2012; Annex 1) enables agreements between HEIs and academics on goals - similar to private corporations (Vormbusch, 2012). Another example for the German reward for compliance scheme is the so-called Excellence Initiative (IECEEI, 2016; Mergele \& Winkelmayer, 2021; Schubert et al., 2017).

Accordingly, we differentiate the term VoP to capture the different forms of HEI organizational governance that internally emphasize a performance orientation from their affiliated academics. The most explicit examples for VoP are performance indicators and performance-based resource allocation (Hammarfelt \& de Rijcke, 2015; Laudel \& Gläser, 2006; Orr et al., 2007). These instruments commonly valorize the academics' performance on the basis of publication indicators and third-party funding (Gralka et al., 2019; Selten et al., 2020). However, organizational performance valorization is not limited to metric indicators. As Huber and Hillebrand (2019) underline, performance agreements between HEI management and academics are important instruments in the current organizational governance of performance that are based on "future expectations of success instead of measurable success" (p. 260). Thus, VoP also includes informal aspects of an organizational performance orientation.

Following the German tradition of rewards for compliance, the Excellence Initiative in particular actively constructs an environment based on the natural science research model and publication paradigm by rewarding universities according to publication outputs,

\footnotetext{
1 In the structures of academic knowledge, beliefs and authority, the academic oligarchy refers to "the imperialistic thrust of modes of authority [...] in the way that personal and collegial forms, rooted in the disciplinary bottom of a system, work their way upward to have an important effect on enterprise and then finally system levels" (Clark, 1983, p. 122).
} 
third-party funding input, and large research clusters (DFG, 2013; IECEEI, 2016; Mergele \& Winkelmayer, 2021). Although, for example, Gerhards (2014) claims that German higher education and science governance are overly fixated on third-party funding, Schubert et al. (2017), for example, show that the so-called Excellence Initiative has had some impact on academics' publication behavior across all disciplines. In line with efforts by the 16 German federal governments to strength HEI leadership in the context of HEI autonomy, the organizational level is formally responsible for the (non-)establishment of evaluation and reward schemes for publications, third-party funding, etc. (Bloch et al., 2021; Gläser \& Laudel, 2019).

\section{Germany as weak evaluation state}

In Germany, the 16 states enable performance-based reward distribution and performance agreements by law but do not define measures and criteria, devolving this task to the academic senate and HEI leadership (e.g., Berlin 2011, § 8; Berlin 2018 [1996], § 3.3; Hesse $2009, \S 36, \S 37)$. Within the legal framework set by the state, HEI leadership, supported by boards and academic senates, exercises the relative autonomy of (not) setting evaluation criteria and establishing performance agreements in very different ways. As a result, university autonomy and academic self-governance has created a patchwork of (non-) application of organizational performance-based reward distribution across HEIs in which organizational VoP does or does not interlock organizational and individual development (Vormbusch, 2012; Huber \& Hillebrand, 2019).

Accordingly, Germany can be attributed Whitley's (2007) label "weak evaluation state" where state VoP pressure is generally lower compared to strong evaluation states (e.g., Deem et al., 2008; Hicks, 2012; Zacharewicz et al., 2019). Already at the turn to the twenty-first century, Butler (2003a) observed a dramatic increase in the quantity of journal articles as a reaction to the introduction of efficacy- and performance-based funding in Australia. For South Korea, several studies found evidence for an increase in refereed journal publications (Kim \& Bak, 2016; Park et al., 2016; Shin et al., 2021) and co-authorship (Lyu et al., 2017), which is interpreted as a response to the state-set introduction of performance-based funding formula. In the UK, the application of principal evaluation criteria in the Research Assessment Exercise (now termed Research Excellence Framework (e.g., Bloch et al., 2021)) also produced a response in terms of publication behavior (Moed, 2008). In Northern European countries, we can observe a combination of managerial approaches to reward efficacy and excellence in the introduction of national publication registers (e.g., Finland: Mathies et al., 2020; Norway: Aagaard et al., 2015; Denmark: Ingwersen \& Larsen, 2014). These publication registers can be used to reward both quality and efficacy by establishing a point system and different ranks of publications. In doing so, quality publications, defined by Journal Impact Factor ranking schemes, are rewarded, while academics publishing in lower class media may challenge the efficacy, for example as observed in Australia (Butler, 2003b). Mathies et al. (2020) show for Finland that after establishing a national publishing register that rewards organizations whose researchers publish according to the system, the number of English language contributions increased, especially in humanities and social sciences, whereas the number of book publications decreased. In Norway, journal articles in the reputable Web of Science increased (Aagaard et al., 2015). 


\section{Disciplinary influences on academics' publication behavior}

In absence of a national German higher education and science regime, in RQ1 (can we observe a convergence of other disciplines to the natural science model of publication?) we address disciplinary organization at the system level. Heintz and Werron (2011) identify journal-based competition in natural sciences as the basis for the global success of the natural sciences' ideal. The acceptance of journal publication as the dominant reward principle has made the natural sciences the "model" (Cole, 1983) for other disciplines, for example also in the social science disciplines of business and economics (Annex 1). In adopting the natural science model, academics in humanities, social and other sciences are challenging disciplinary traditions of knowledge generation and distribution (e.g., Chi, 2015; Dyachenko, 2014; Haddow \& Hammarfelt, 2019; Larivière \& Sugimoto, 2019; Sivertsen, 2016). Altogether, the share of publications by humanities and social sciences scholars from non-English speaking countries has increased in general and in peer-reviewed journal publications in particular as, for example, the European cross-country comparison by Kulczycki et al. (2018) shows. In addition, co-authorship has increased in publications by humanities and social sciences scholars (e.g., Henriksen, 2016; Ossenblok et al., 2014). In social sciences, the number of monographs published per author has decreased over time (e.g., Engels et al., 2012). Pressure from the natural sciences publication paradigm does not imply that publication patterns have changed completely. For example, Puuska (2014) shows that in humanities books remain important, but observes a shift from monographs to edited volumes.

For Germany, Flink and Simon (2014) stress the effects of peer pressure in academic communities toward what we termed the natural sciences publication paradigm, i.e., publishing more English language articles in peer-reviewed and indexed journals - in addition to the politically initiated output orientation (see also de Rijcke et al., 2016; Osuna et al., 2011; Schimank, 2010; Volkmann et al., 2014). Such pressures can be observed to affect even German qualification traditions. Nowadays, a Habilitation or $\mathrm{PhD}$ thesis can be either a book or a collection of published papers. Accordingly, already $\mathrm{PhD}$ candidates are slowly becoming acquainted with the Anglo-American culture of "publish or perish" (BackesGellner \& Schlinghoff, 2010; Enders \& Musselin, 2008; van Dalen \& Henkens, 2012). ${ }^{2}$

\section{Data}

To answer our research questions, we use the German data from three international follow-up surveys, which allow us to compare the three surveys and observe trends in the academic profession over time: The Carnegie Foundation study from 1992 (from now on "Carnegie 1992"), the CAP study from 2007 (Changing Academic Profession, "CAP 2007") and the APIKS ${ }^{3}$ study from 2018 (Academic Profession in Knowledge Societies, "APIKS 2018"). The international study Carnegie 1992 was conducted on initiative of the Carnegie Foundation, which regularly conducts surveys on the academic profession in the

\footnotetext{
2 The publish or perish culture affects academics aspiring to become professors. For sociologists, for example, each SSCI indexed and refereed journal article and each monograph increases their chances for tenure by 10 to $15 \%$ (Lutter \& Schröder, 2016; see also Jungbauer-Gans and Gross 2013).

3 The German APIKS data is available for other scientists in 2022 hosted by GESIS - Leibnitz Institut für Sozialwissenschaften.
} 
USA, now with the goal to broaden the scope to an international perspective (Boyer et al., 1994; Enders \& Teichler, 1995a). CAP 2007 was initiated by an international research group with the goal to observe changing conditions in the academic profession in comparison to Carnegie 1992. Subsequently, the questionnaire has been expanded with current topics (Jacob \& Teichler, 2011, p. 13). Similarly, APIKS 2018 was conducted as an international survey with the prospect of observing change (compared to Carnegie 1992, and CAP 2007) and an additional focus on the knowledge society (therefore: Academic Professions in Knowledge Societies). All three German parts of these international surveys were conducted by The International Centre for Higher Education Research-Kassel (INCHER) (at the time of Carnegie 1992 INCHER was called Centre for Research on Higher Education and Work). The German part of the Carnegie 1992 survey only questioned academics in West Germany; higher education institutions in East Germany were undergoing a period of change due to the reunification of Germany (Jacob \& Teichler, 2011, p. 12).

The target population is academics in full-time or at least half-time employment at universities and Universities of Applied Sciences in Germany. In Carnegie 1992, two-stage sampling was used: In the first stage, 18 HEIs were sampled randomly. From these HEIs, a full sample (cluster) of the academic profession was taken (Enders \& Teichler, 1995b). In CAP 2007, sampling was different for full professors and non-full professors. Full professors were sampled via stratified random sampling (strata: gender, disciplines) using Kürschner Deutscher Gelehrten Kalender 2007 (an encyclopedia that contains a biographical list of all professors in Germany). Non-full professors in CAP 2007 were sampled via twostage stratified random sampling. In the first stage 101 out of 339 HEIs were sampled and then in these HEIs the non-full professors were sampled (strata on HEI level: type, region, third-party funding of university, type of staff; strata on the individual level: gender and discipline) (Jacob \& Teichler, 2011). Full professors were over-sampled in CAP, as they are the specific target group. However, this should not affect our analyses as we analyze only full professors to answer RQ1 and RQ2. In APIKS 2018, two-stage sampling was used. In the first stage, HEIs were sampled to yield a random sample of 24 HEIs stratified by type, region and size. From these HEIs, a full cluster of academics was targeted (Schneijderberg \& Götze, 2020).

The distribution of gender, the organizational types included (University and University of Applied Sciences) and the disciplines analyzed were almost representative in all three surveys (Table 1). ${ }^{4}$ Response rates were similar in each study, Carnegie 1992: 28\%, CAP 2007: 32\%, APIKS: 28\% (Enders \& Teichler, 1995b; Teichler et al., 2013).

The three studies are thus not constructed as a panel. Each of the three studies draws a new cross-sectional sample of academics (full professors and non-full professors) working at a university or a University of Applied Sciences in Germany. For our analysis, we can include the following samples: Full professors: Carnegie $1992 n=661$; CAP $2007 n=305$; APIKS $2018 n=990 .^{5}$

\footnotetext{
${ }^{4}$ In Carnegie 1992 the disciplines in the final sample are not completely distributed in the same way as in the population, medicine in particular is too low (Enders \& Teichler, 1995b). However, medicine is not used for our analysis and for other disciplines we either run separate analyses or use discipline as a control. In CAP 2007, there is an almost representative distribution of organizational types (University and Universities of Applied Sciences), disciplines, and gender (Bracht, 2008). In APIKS 2018, the residual category "other discipline" (such as sports) is slightly underrepresented.

5 Each study aimed for a different sample size. For example, the CAP 2007 study aimed for 800 respondents. The APIKS 2018 study aimed for a full sample of the 24 HEIs.
} 


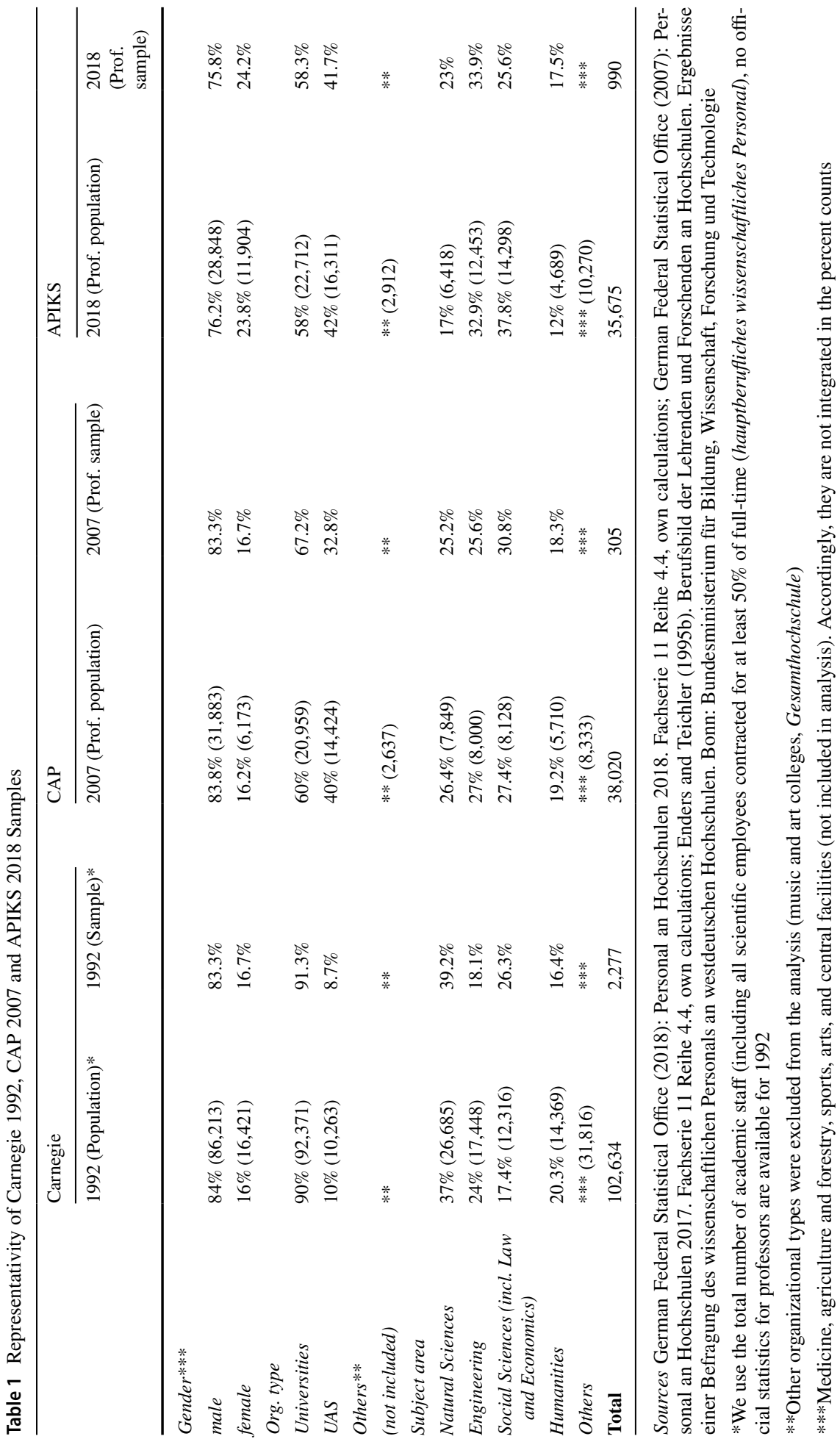


The studies focus on everyday working activities and academic professionals' attitudes toward their job responsibilities in higher education: research, teaching and learning, governance, transfer activities, as well as career paths (Altbach, 1996; Enders \& Teichler, 1995a, 1995b; Jacob \& Teichler, 2011; Teichler et al., 2013). A major advantage of these surveys for our purpose is a differentiated question about all types of publications. In contrast, bibliometric databases are not well suited for analyzing publications in the humanities and social sciences (Chi, 2015). In these academic fields, the publication patterns are more diverse and do not only comprise English language and international publications as focused on by the Web of Science (Hicks \& Wang, 2011; Kyvik, 2003).

For our research purpose, the total sample analyzed differs for each of the two research questions because the target group and the available variables in the datasets differ with respect to each research question (Table 2). For answering RQ1 and RQ2 we focus on full professors because lower rank academics are not considered the typical academics in cross-country comparative surveys (Kyvik \& Aksnes, 2015; Kyvik \& Olsen, 2008). RQ2 addresses actual organizational policy. Therefore, we use only APIKS 2018 data because organizational-level data is not available in Carnegie 1992 and CAP 2007. For answering RQ1, we are interested in studying a potential change in publication patterns in disciplines over time. Therefore, we run separate analyses for each discipline. An addition, the overall analysis shows whether publication patterns are now more similar between natural sciences and other disciplines or not.

Our output variables measure the quantity of different publication types per author. The three surveys use two different measures for the quantity of publications. First, journal articles and books (one item for books as author, one item for books as editor) are measured as numbers or so called count variables ("how many of the following scholarly contributions have you completed in the past three years?"). Second, peer-reviewed contributions, nonGerman language publications ("published abroad") and co-authored publications (one item for national and one item for international collaboration) are measured as a percentage ("What percentage of your publications in the last three years were..."). The publication output always relates to the last three years. This is an appropriate measure (Abramo et al., 2012). Shorter periods of measurement are not robust against random components and longer periods are not able to detect important variation during a period (Abramo et al., 2012). In line with our argumentation, journal articles, peer-reviewed contributions, nonGerman language publications and co-authored publications are considered as publication behavior according to the natural science paradigm, which valorizes books and edited books less.

The three surveys (Carnegie 1992, CAP 2007 and APIKS 2018) provide an opportunity to observe changes in publication behavior in the academic profession over time. As not all of the three surveys contain all variables, not all analyses contain data from all three studies (Table 2). The variables measured as a percentage (peer-reviewed contributions, nonGerman language publications and co-authored publications) are only collected in CAP 2007 and APIKS 2018. Further, the variable measuring journal articles changes slightly over time: The item regarding the number of "chapters in edited books/journal articles" is measured as one composite item in the questionnaires for Carnegie 1992 and CAP 2007. However, APIKS 2018 uses two specific items so that respondents can choose between number of "journal articles" and number of "book chapters". Therefore, to answer RQ2 we have to rely only on APIKS 2018 data, which can uniquely identify journal articles. 


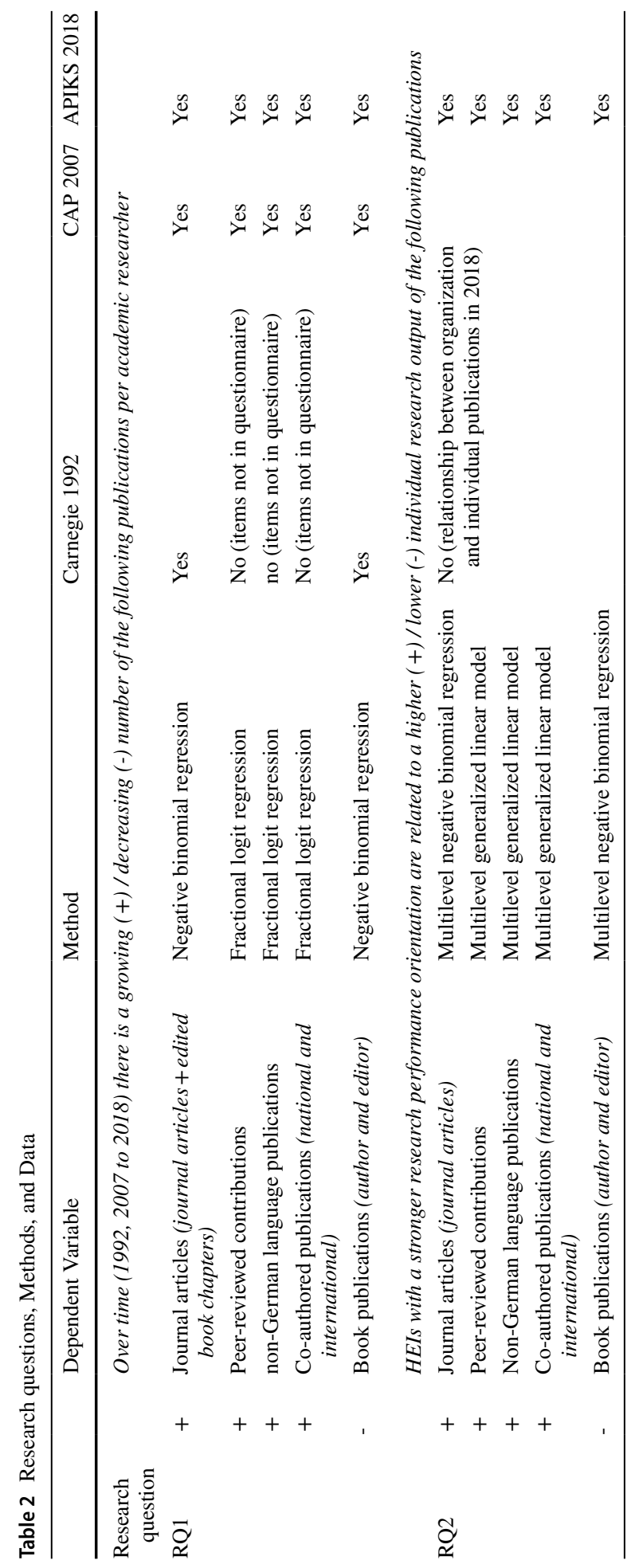


To operationalize the extent of an HEI's VoP we use two HEI aggregated indicators: organizational performance-based allocation of funding to academic units and organizational research performance orientation. Organizational performance-based funding was operationalized using an HEI aggregated mean of the individual assessments of the following statement: "To what extent does your institution emphasize the following practices? Performance-based allocation of resources to academic units" (5-point Likert scale ranging from $1=$ not at all to $5=$ very much). Organizational research performance orientation was used as a broader operationalization for organizational VoP, which also includes non-monetary forms of organizational emphasis on research performance. Organizational research performance orientation was operationalized by an HEI aggregated mean of the individual assessments of the following statement: "At your institution, there is a very strong research performance orientation" (Likert scale ranging from $1=$ strongly disagree to $5=$ strongly agree). The HEI aggregated mean is a common way to approach the organizational level if organizational-level data are not available (e.g. Kwiek, 2018; Shin \& Cummings, 2010).

Our main explanatory variable to answer RQ1 is the year, corresponding to the surveys: 1992, 2007 and 2018. These three points in time fit to developments in the German higher education system (see section “A literature-based description of VoP in Germany"). We analyze the following academic fields: natural sciences, engineering, humanities, social sciences, and economics. To study a possible adaptation toward the natural sciences, we run these analyses separately for each academic field. When analyzing the other questions, we use academic field as a control variable.

We further control for personal and organizational characteristics related to publication output (Bentley, 2012; Hopkins et al., 2013; Jacobs \& Ingwersen, 2000): Gender, type of HEI (University vs. University of Applied Sciences), years of employment in HEIs, and type of qualification (habilitation vs. $\mathrm{PhD}$ and below). Descriptive statistics of the employment data, divided by study (Carnegie 1992, CAP 2007, and APIKS 2018) are presented in Table 3.

\section{Methods}

We use several publication types as outcome variables. All methods and data are displayed in Table 2. We use regression models to predict our outcomes. We assume that changes in publication behavior aligning it with the natural science paradigm are related to the passage of time (RQ1) or organizational VoP (RQ2). Additionally, publication patterns can be assumed to be affected by other organizational and individual characteristics (e.g., Puuska, 2010). These need to be controlled if shifts towards the natural sciences publication paradigm are to be identified as a general trend and not related to, for example, the different distribution of gender in academia over time.

The type and distribution of the outcome variables indicate a specific regression model. Journal articles and (edited) books are measured as numbers. These count data indicate how many times an event occurs in a given interval (Long \& Freese, 2014, Sec. 9; examples: Henriksen, 2018; Bornmann \& Daniel, 2016), for example, how many articles an academic published in the last three years. We apply negative binomial regressions to count data. These models are preferred over Poisson regressions as publication/citation data is typically overdispersed: Overdispersion means that the variance is higher than the mean. Publication data is typically skewed (see also Bornmann et al., 2010, p. 109) as a few academics have many publications whereas the majority of academics have few publications 


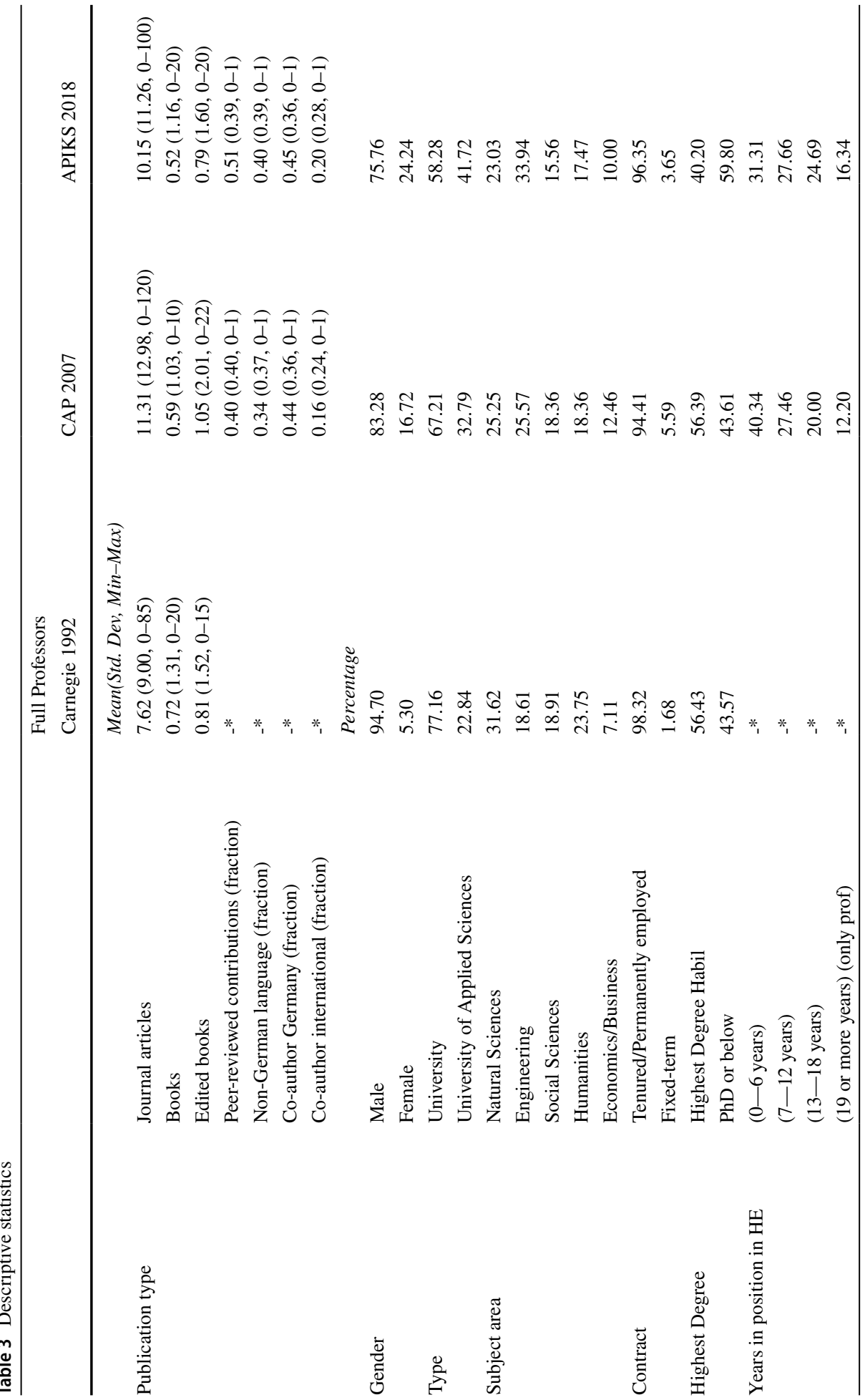




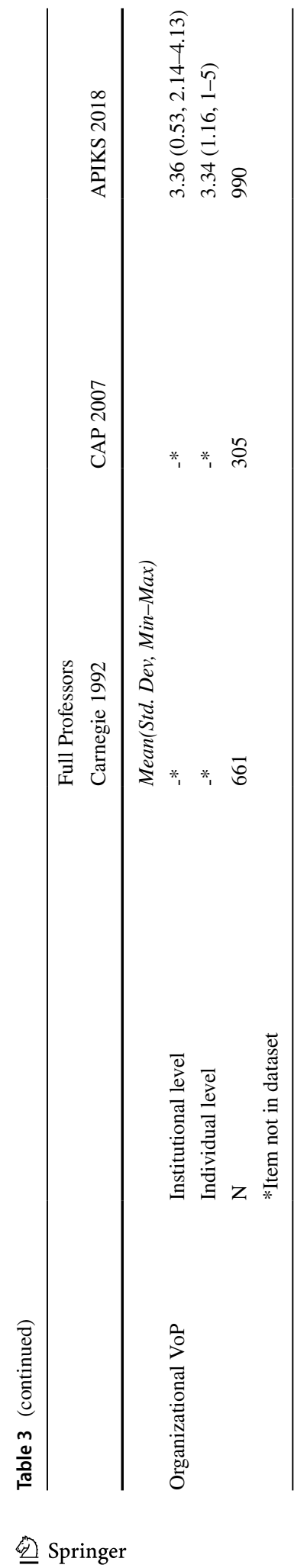


(de Solla Price, 1963; Lotka, 1926; Saam \& Reiter, 1999). Overdispersion in our data has also been tested using a likelihood ratio test (Long \& Freese, 2014, p. 511).

Peer-reviewed contributions, non-German language publications and co-authored publications are measured in percentages. We divide them by 100 and use them as fractions (values between 0 and 1 instead of $0 \%$ and 100\%). For the outcomes measured in fractions, we use fractional response models (Papke \& Wooldridge, 1996). These models are used to analyze a fraction of a total, e.g., peer-reviewed publications as a fraction of all publications. These models also manage fractional outcomes that are bounded between 0 and 1 when the outcome is equal to the extreme values of 0 or 1 .

RQ2 addresses an association between organizational VoP (performance orientation and performance-based allocation of funding) and the publication output of the individual academic. These parameters suggest that a multilevel model would be appropriate (Rabe-Hesketh \& Skrondal, 2012). Such a model takes into account that processes operate "at different levels, for instance, people's characteristics interact with institutional characteristics" (Rabe-Hesketh \& Skrondal, 2012, p. xxv). In our case, we have professors at HEIs who are assumed to be affected by the HEI's VoP, which is expected to result in a higher publication output according to the natural science paradigm. Thus, here the dependency of an individual's output (publications) on a higher unit (HEI) is the core issue to answer RQ2 (Snijders \& Bosker, 2012). Multilevel models can model the variance of a first level (individual) and of a second level (HEI) variance component (Rabe-Hesketh \& Skrondal, 2012). In our final analytic sample to answer RQ2, we have 23 HEIs $^{6}$ (second level) with between 12 and 91 full professors. Accordingly, our output variables are count data (journal articles and (edited) books), which are analyzed using multilevel negative binomial regression. Fractional data (peer-reviewed, non-German language and co-authored publications) are modeled as a multilevel generalized linear model with a binomial distribution and a logit link. With this specification, we can adapt the fractional model for multilevel use. A generalized linear model is appropriate as it can relax the assumptions of an ordinary linear regression (Hardin \& Hilbe, 2012). For fractional data, the distribution is binomial and the relation between the linear predictor and the expected value is modeled as a logit link (Hardin \& Hilbe, 2012, p. 167; Stata command xtgee). Following RQ1, the analyses are single level models (individual level). All analyses were conducted using Stata 14 (StataCorp, 2015).

\section{Results}

\section{Disciplinary differences in publication outputs}

RQ1 is based on the assumption that publications by individual academics in every discipline develop over time (from 1992, 2007 to 2018) towards publication behavior valorized in natural sciences, i.e., more journal articles and fewer books, and more

\footnotetext{
${ }^{6}$ One small HEI could not be used in the multilevel analysis due to low case numbers.
} 


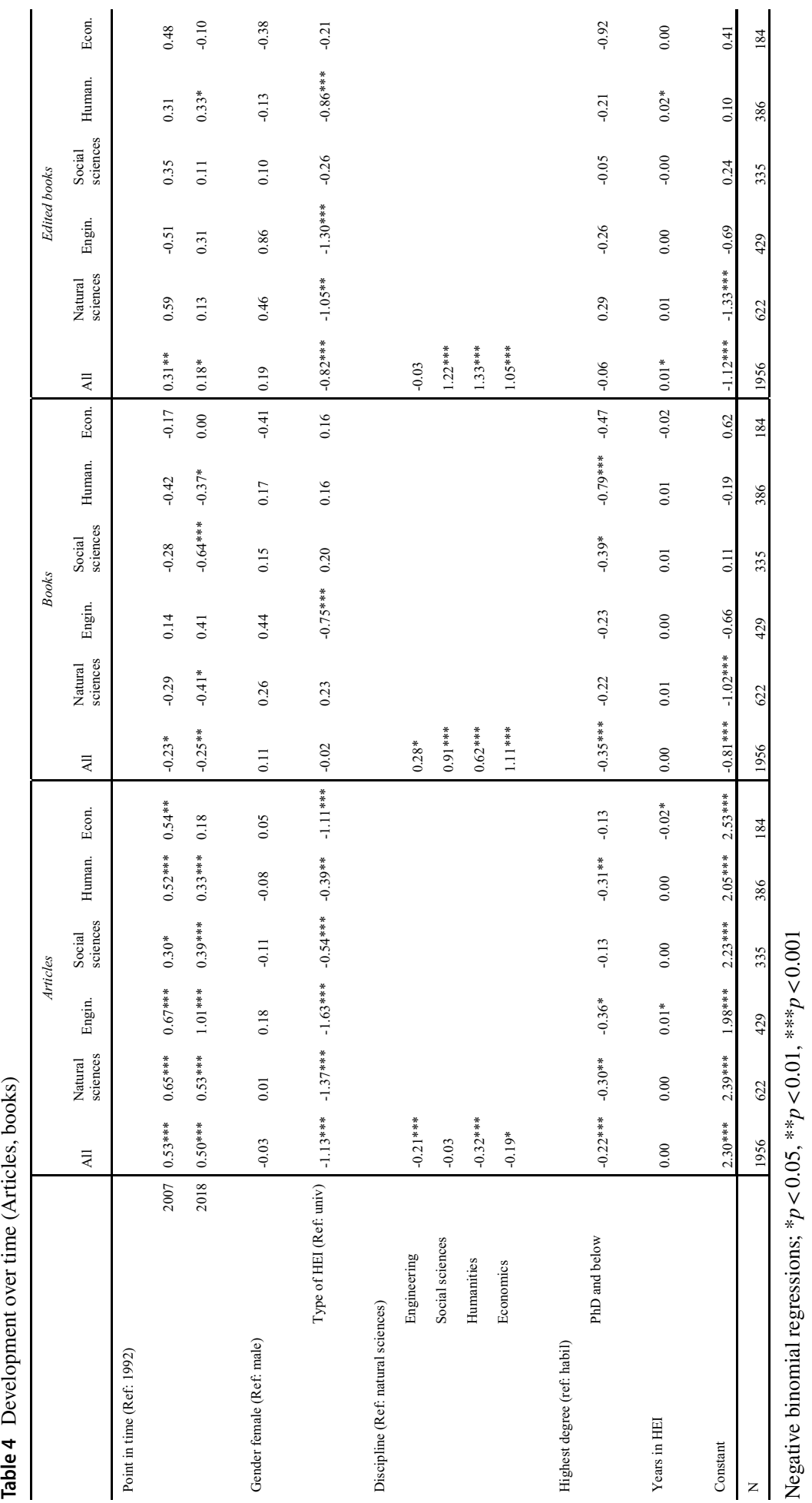




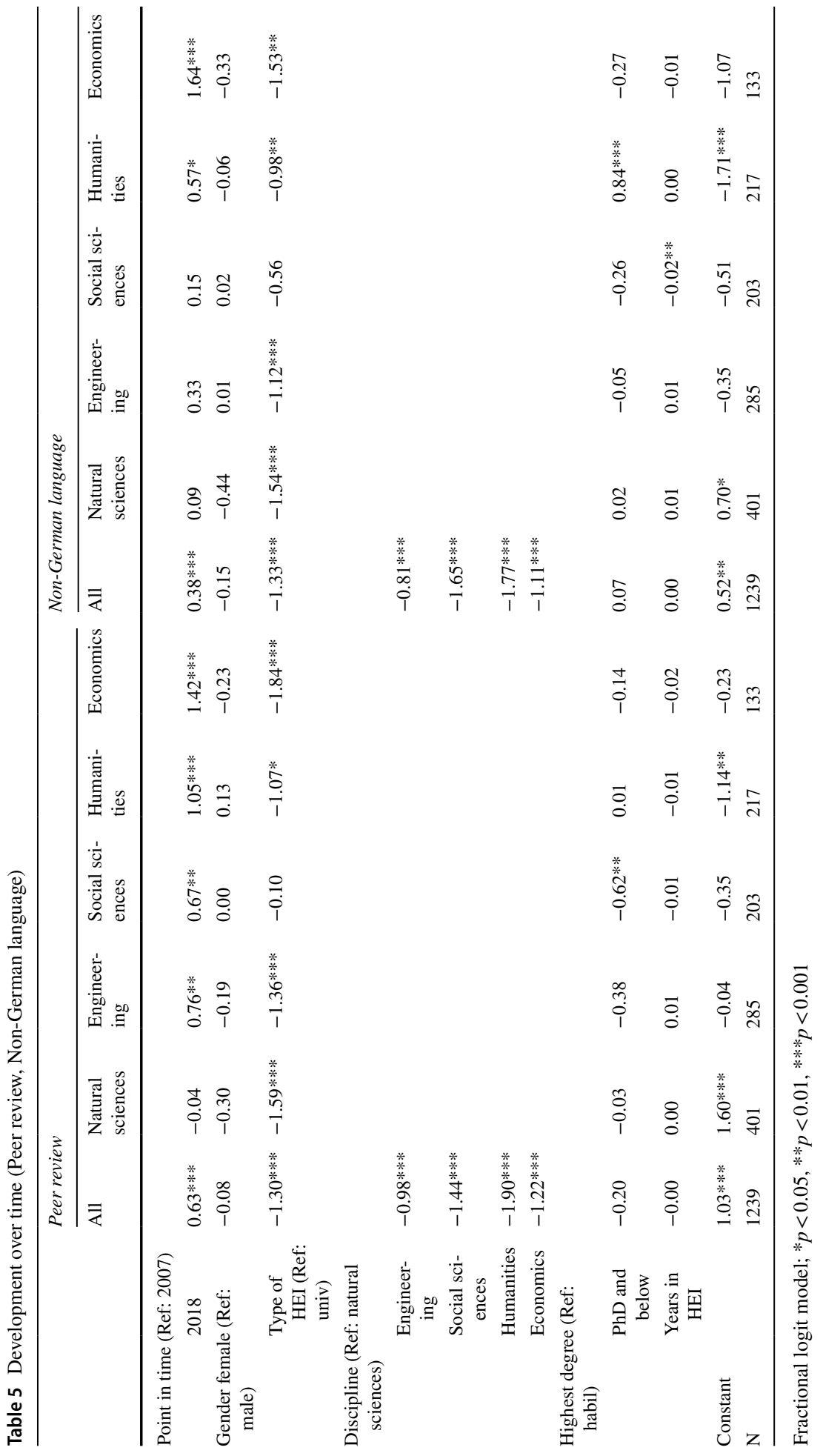


peer-reviewed contributions, non-German language publications and co-authored publications. In Table 4, we see the development over time in the number of articles or book chapters published by professors in different academic fields. Taking 1992 as a baseline for the relevant explanatory variable "point in time", the number increased in all disciplines in 2007, and in 2018 the coefficients further increased in engineering and social sciences.

As addressed in RQ1 (Table 5), the percentage of peer-reviewed publications increased in all disciplines except natural sciences between 2007 and 2018. While natural sciences seem to have peaked and no longer show a visible upward trend, academics in other disciplines have published more and more peer-reviewed contributions. The percentage of non-German language publications increased in the humanities and economics between 2007 and 2018 (Table 5). We do not find these developments in other disciplines. With regard to the indicator for co-authorship with German researchers, we do not find any significant coefficients (Table 6). However, we find a positive relation for co-authorship with international researchers in economics (Table 6). Thus, evidence for increased co-authorship in general is sparse. The number of books published per academic has significantly decreased in social sciences and the humanities (and also in the natural sciences) in 2018 compared to 1992 (Table 6). Thus, in the two fields where traditionally books were published, the assumed trend toward fewer books can be observed. At the same time, we do not find much significant evidence for changes in the number of edited books per author in the same two fields (Table 6). In the humanities, in 2018 academics published more chapters in edited books compared to 1992. With an increase in the number of journal articles and book chapters per author, this development makes sense because the book chapters have to appear in an edited book.

In sum, several but not all indicators point towards changing publication behavior according to the natural sciences paradigm. Academics are publishing more articles and especially a higher share in peer-reviewed publications. Further, in some disciplines the share published abroad has increased. Books per author have decreased over time in the disciplines where they are generally relevant. 


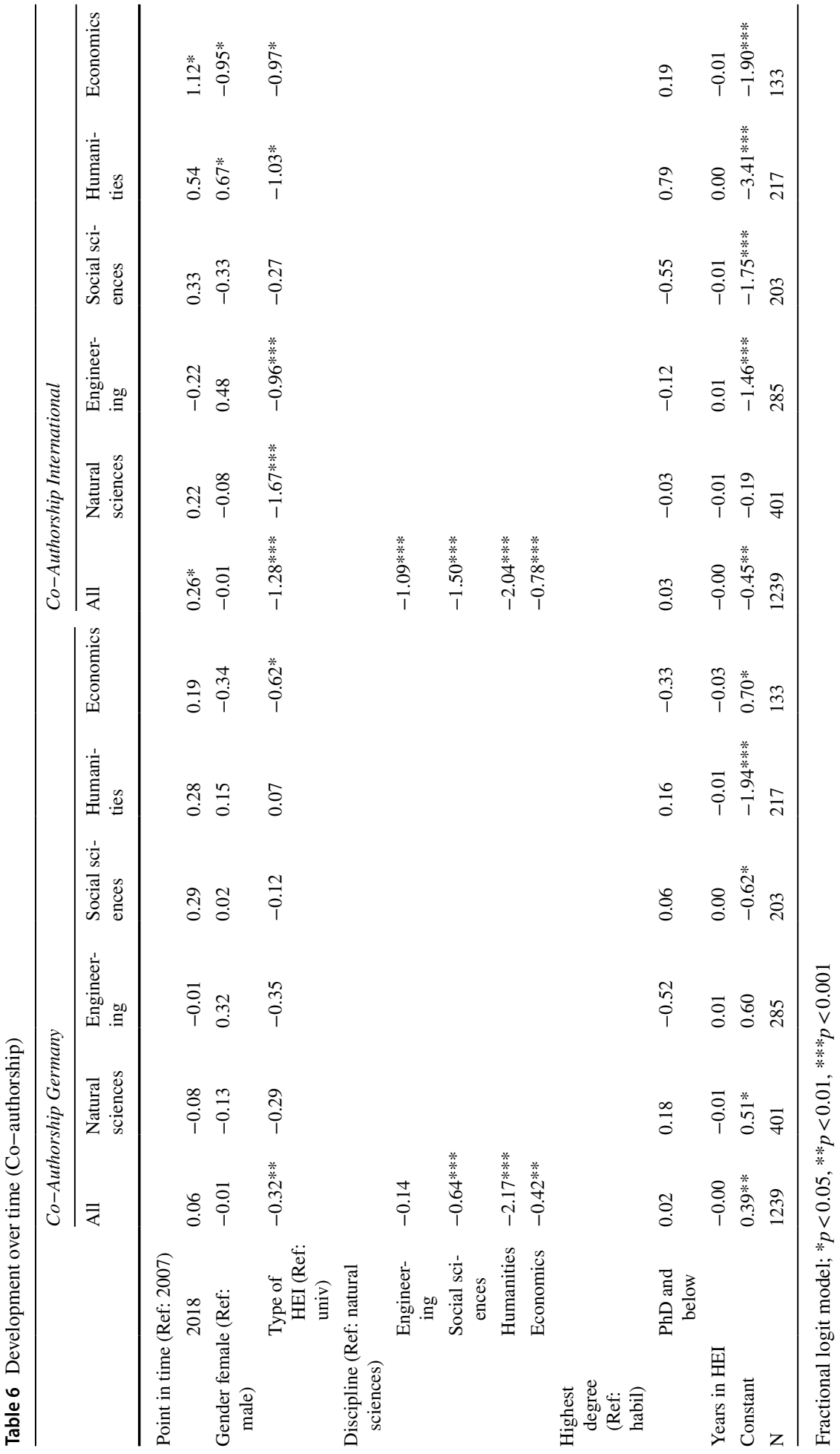




\section{Organizational valorization of performance and individual publication outputs}

RQ2 posits that individual academics publish more publications valorized by the natural science paradigm (i.e., more journal articles and fewer books, and more peerreviewed and co-authored publications) the more strongly an HEI valorizes performance (organizational research performance orientation and performance-based allocation of funding). The two HEI aggregated indicators are highly correlated (Spearman's rho $=0.79$ ). To avoid multi-collinearity, the correlation of the two indicators performance-based allocation of funding (Table 7) and research performance orientation (Table 8) with individual publication behavior was calculated in two separate models. For future research, combining performance-based allocation of funding and research performance orientation of HEIs in one latent construct could be considered.

As presented in Table 8, higher values on organizational research performance orientation are associated with a significantly higher number of articles per author, with a higher share of peer-reviewed articles as well as a higher share of publications in cooperation with academics abroad. In comparison to general organizational research performance orientation, the association between organizational performance-based allocation of funding and publication behavior valorized in the natural sciences is weaker, but points in the same direction (Table 7). Here, only the share of peer-reviewed contributions is significantly positively correlated with the extent of organizational performance-based funding. In sum, research performance recognition as part of HEI VoP can only be related to publication behavior valorized in the natural sciences for the key indicators, namely journal articles, peer-reviewed articles and international cooperation. ${ }^{7}$

\footnotetext{
${ }^{7}$ In addition, we also conducted this analysis for non-full professors at universities. They also show the positive relationship between VoP and number of articles, and additionally for co-authorship in Germany and international co-authorship.
} 


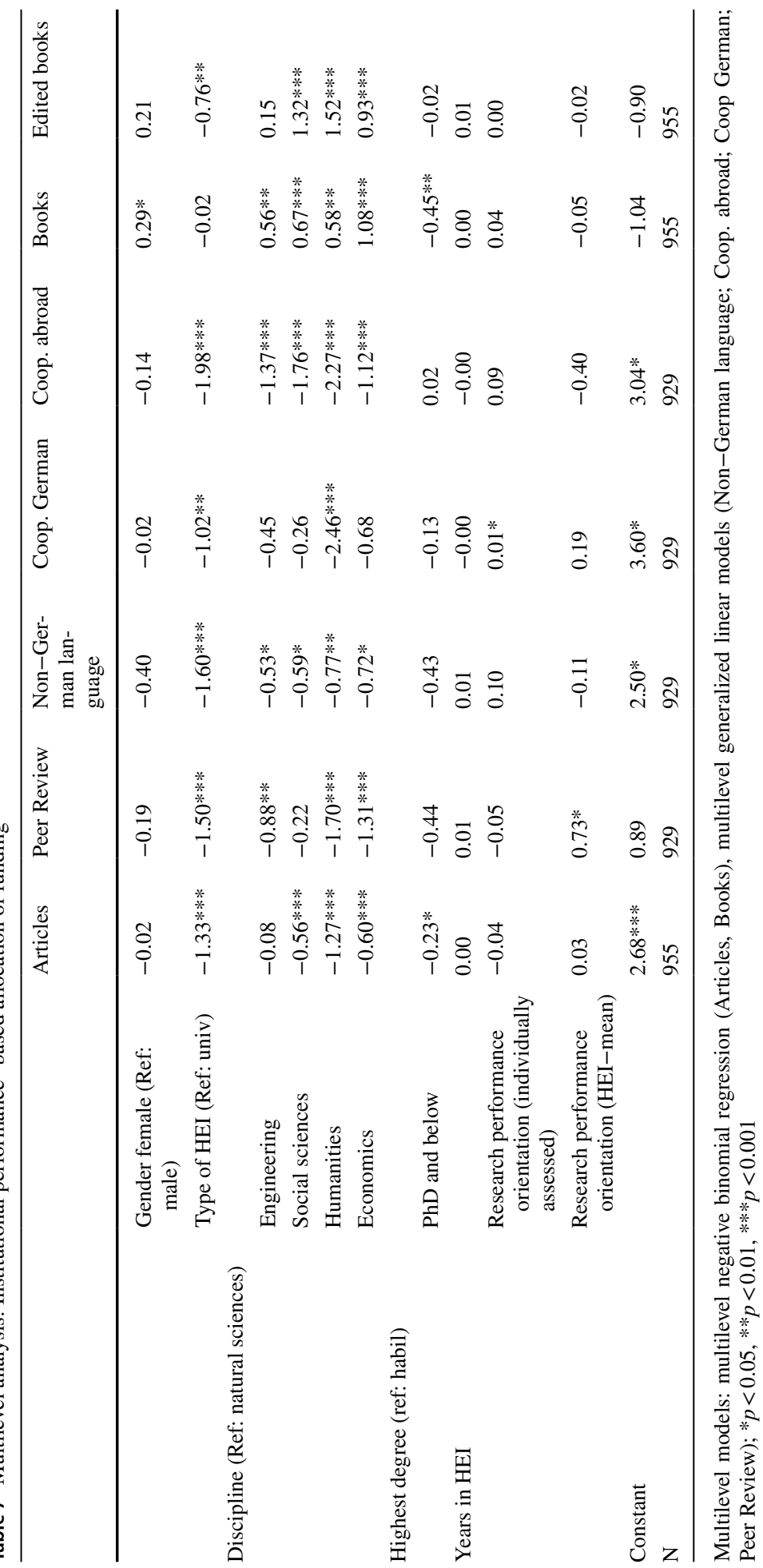




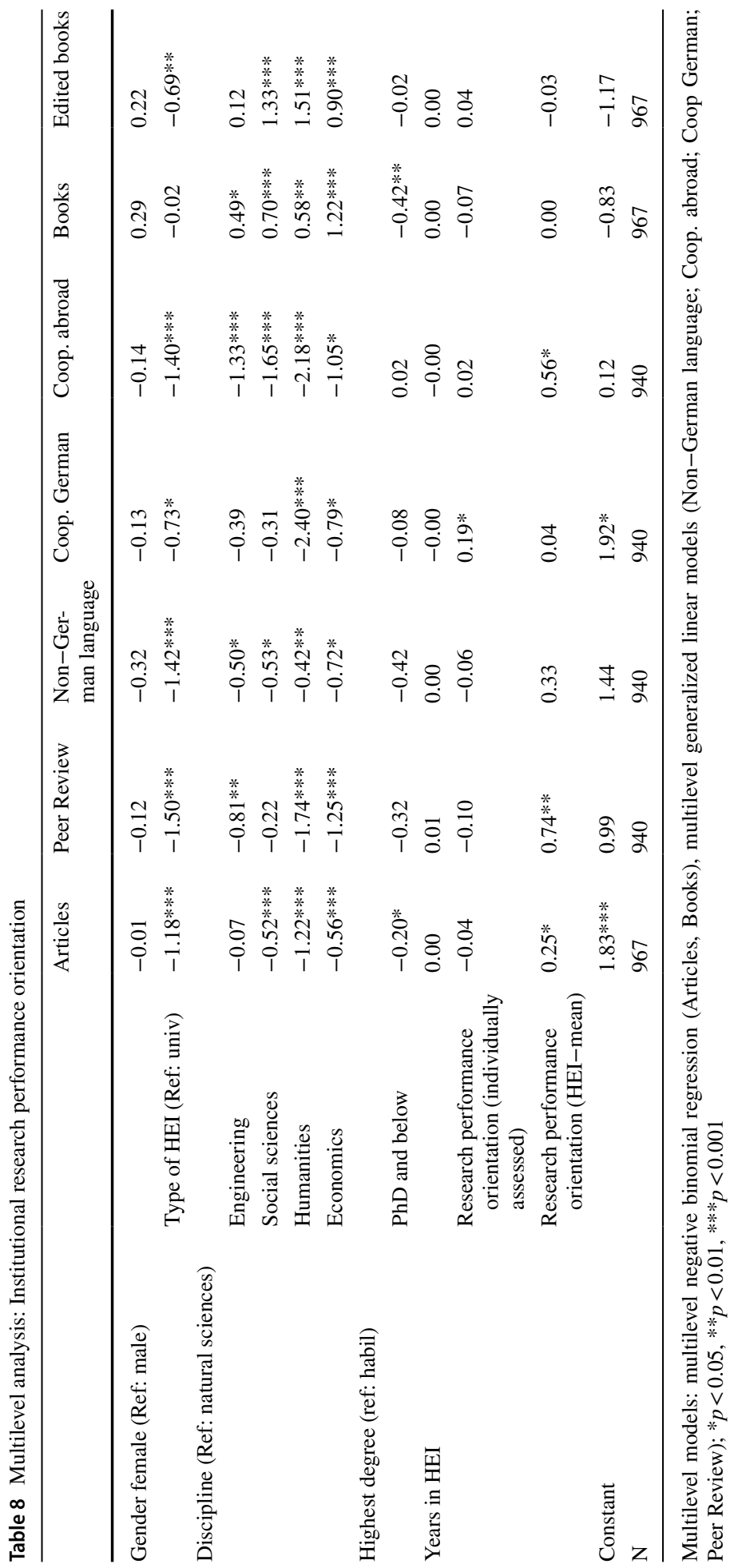




\section{Discussion of results and conclusions}

In this study, we analyzed the individual publication outputs of academics in Germany over three decades. We theoretically assumed that we could observe a change in publication behavior within the academic profession by differentiating disciplines (RQ1) and organizational VoP (RQ2). Summarizing the empirical results, we can see a trend of changing publication behavior within the German academic profession. Our results show that publication behavior valorized according to the natural science paradigm was already institutionalized at the time of the CAP 2007 survey and seems to have become intensified by the time of the APIKS 2018 survey. As addressed in RQ1, from Carnegie 1992 over CAP 2007 to APIKS 2018, academics across disciplines are publishing more articles, and especially peer-reviewed contributions have increased in all disciplines. The decreasing number of books in the social sciences and the humanities is interpreted as a sign of a crowding-out effect of traditional publication cultures by a publication culture valorized in natural sciences. However, the book is not disappearing. In spite of the limitation of low numbers of respondents per discipline in Carnegie 1992 and CAP 2008, we can clearly see the general trend toward the natural sciences publication paradigm in several disciplines.

The rise in the number of articles and peer-reviewed publications indicates that, according to the natural science publication paradigm, Journal Impact Factor and citation countoriented, i.e., metrical publishing seems to have become the "path to success" (Karpik, 2011, p. 73) and now forms the core of "normal science" (Karpik, 2011, p. 83) that affects all disciplines. Further, the increase in international publishing means that academics in Germany are publishing in English, thus increasing their international visibility. In spite of the observed trend toward the natural science publication paradigm, books are still very common in social sciences and humanities, for example, the vast majority of $\mathrm{PhD}$ theses are still published as a monograph (GFSO, 2016).

Regarding the changes in publication behavior, bibliometric studies focusing on Web of Science publications came to similar results, finding that German academics increasingly publish with international publishers (e.g., Michels \& Schmoch, 2014). However, in our study this is not the case in all disciplines (not in social sciences and engineering). Research in these disciplines still focuses on local problems (social sciences: Dyachenko, 2014; engineering: Kaltenbrunner, 2018), which also contributes to German academic identity construction, for example of the German engineer. Surprisingly, in our data we do not find evidence for internationalization in increasing co-authorship, which can be found in studies from other countries (e.g., Henriksen, 2016; Ossenblok et al., 2014; Sivertsen, 2016). One possible interpretation of our finding is that the peak in collaboration was reached already during the CAP 2007 survey.

Addressing RQ2, we found a significant positive correlation between the organizational performance orientation indicator and peer-reviewed, international cooperative, journal publication. Thus, organizational differentiation in valorization of performance is connected to the publication behavior valorized by the natural sciences, while other research outputs are unaffected. Taking the results on the transformation of publication behavior into account, VoP can be interpreted as one core driver of the general transformation towards the natural science publication paradigm. However, the decrease in book publications does not seem to be related to organizational VoP.

Given that the correlations at the organizational level are based on one point in time (2018), we cannot rule out that the decrease in the number of book publications is a result of the stronger performance orientation and orientation towards the natural science paradigm of all HEIs due to increasing organizational competition in the overall system. For example, 
the stronger performance orientation of so-called Excellence Universities could be assumed to exert further pressure on other HEIs or lead to further vertical stratification among German universities (Schneijderberg et al., 2021). To test this assumption, future research, designed as a panel study for example, could study the parallel historical evolution of individual publication behavior and of organizational VoP. The analysis in this study has the limitation that we could not investigate the direction of the relationship. Thus, it is unclear whether a) the hiring of productive professors oriented to the natural science publication paradigm affects organizational VoP or b) strong VoP in HEIs leads to more internationally co-authored, peer-reviewed journal publications or c) HEIs with performance incentives could also select more VoP-conformist productive academics in their hiring (see also Allison \& Long, 1990). Such panel studies could shed light on the mechanisms. Of course, such prospective studies would have to differentiate between weak evaluation states, where state $\mathrm{VoP}$ is not equal to HEI VoP, and strong evaluation states with centralized research funding allocation according to national VoP, such as the UK (e.g., Bloch et al., 2021). In addition, counter developments are being reported with strong evaluation states being able to loosen the firm VoP grip on HEIs. For example, Woelert and McKenzie (2018) show how Australian universities replicate the national performance-based funding mechanisms. Similar to Germany, the institutional oligarchy in HEI leadership defines which (publication) outputs count and are rewarded, and which are academically nice to have but irrelevant for national and international competition in ratings and rankings, and for professors' salaries.

Initial cautious conclusions about publication behavior changing towards the natural science publication paradigm can be drawn based on the findings of RQ2 (organizational level) and the relative insignificance of performance-based funding for individual professors' salaries (Klenke, 2012; Wilkesmann \& Schmid, 2012; for Norway, see Aagaard et al., 2015; for US see, Leahey, 2007). The results underline that especially the non-monetary and to a lesser extent the monetary elements of $\mathrm{VoP}$ are associated with academics publishing increasingly in peer-reviewed, English language journals (e.g., metrified by the Journal Impact Factor), while other publication formats are unaffected. Thus, VoP seems to drive academics to orient themselves towards journal publications, which are part of the main indicators in the (rankingdriven) international competition between HEIs (e.g., Selten et al., 2020). We consider the close relationship between the so-called Excellence Initiative and VoP (DFG, 2013; IECEEI, 2016) one possible explanation. The significant positive correlation between the share of publications co-authored with academics abroad and organizational performance orientation, make it plausible that HEI policies for internationalizing research and HEI policies on VoP correspond. This is in line with research on internationalization, which emphasizes that research intensity and international orientation are connected to the image of a "global model" (Mohrman et al., 2008, p.6) of research universities. For example, Gao (2015) argues that HEI managers are aware of the correlation between international research cooperations and more publications, which result in a higher impact of research (e.g., more citations).

In addition to changing publication behavior being pushed by ranking and the (global) battle for excellence, the results of this study again point to the key role of the academic profession and its institutional academic oligarchy. With few exceptions, the results of this study for Germany show a similar publication trend to other, strong evaluation countries (e.g., Hicks, 2012; Matthies et al., 2020; Zacharewicz et al., 2019). For Germany, this suggests that the absence of a state-set evaluation system and the associated label "weak evaluation state" does blur a non-existing system-level difference for changing academics' publication behavior across all disciplines. Accordingly, "weak evaluation state" cannot be considered the key or single explanatory heuristic. The key explanation for the change in German academics' publication behavior is the German academic profession and its 
institutional oligarchy in disciplinary organizations as well as HEI leadership. This suggests that in the social partnership between the academic profession and the German state, the academic profession is establishing a strong evaluation state, which is not alien to academic VoP and connected reputation gain.

\section{Appendix 1}

An example of valorization of performance $(\mathrm{VoP})$ criteria at the very explicit end of the scale is the highly transparent listing by the Business, Management and Economics Department of the University of Göttingen. Publicly available on the website of the department are:

- VoP concept for research (Konzept LOM Forschung WiWi 2018) ${ }^{8}$

- VoP concept for teaching (Konzept LOM Lehre WiWi 2018) ${ }^{9}$

- Overview of journals by rank (Übersicht verfügbare Publikationsquellen WiWi mit Bewertungen (Stand: Juni 2018) $)^{10}$

- Alphabetical list of journal metrics according to the Business and Management Association (Alphabetische Liste der Zeitschriftenbewertungen durch den Verband der Hochschullehrer der BWL (VHB-Liste: JOURQUAL 3.0)) ${ }^{11}$

- List of journal metrics according to the German Economics Association 2008 (Liste der Zeitschriftenbewertung durch den Verein für Socialpolitik, Stand 2008 (VfS-Liste 2008) $)^{12}$

- List of journal metrics according to the German Economics Association 2011 (Liste der Zeitschriftenbewertung durch den Verein für Socialpolitik, Stand 2011 (VfS-Liste 2011)) $)^{13}$

To facilitate the registration of publications in the VoP database the department also provides instructions for academics on how to create a new entry (Anlegen einer Publikation $)^{14}$ and links to the user manual of FactScience ${ }^{15}$ guidelines for the evaluation of publications in FactScience. ${ }^{16}$

\footnotetext{
${ }^{8}$ https://www.uni-goettingen.de/de/konzept+lom+forschung+wiwi+2018/415683.html (last accessed 08 April 2020).

9 https://www.uni-goettingen.de/de/konzept+lom+lehre+wiwi+2018/415684.html (last accessed 08 April 2020).

${ }^{10} \mathrm{https}: / /$ www.uni-goettingen.de/de/\%c3\%9cbersicht+verf\%c3\%bcgbare+publikationsquellen+wiwi+mit+ bewertungen+\%28stand\%3a+juni+2018\%29/415686.html (last accessed 08 April 2020).

${ }^{11}$ https://www.uni-goettingen.de/de/alphabetische+liste+der+zeitschriftenbewertungen+durch+den+ verband+der+hochschullehrer+der+bwl+\%28vhb-liste\%3a+jourqual+3.0\%29/538660.html (last accessed 08 April 2020).

12 https://www.uni-goettingen.de/de/liste+der+zeitschriftenbewertung+durch+den+verein+f\%c3\%bcr+ socialpolitik\%2c+stand $+2008+\% 28 \mathrm{vfs}-\mathrm{liste}+2008 \% 29 / 422725$.html (last accessed 08 April 2020).

${ }^{13} \mathrm{https} / / / \mathrm{www}$.uni-goettingen.de/de/liste+der+zeitschriftenbewertung+durch+den+verein $+\mathrm{f} \% \mathrm{c} 3 \% \mathrm{bcr}+$ socialpolitik\%2c+stand+2011+\%28vfs-liste+2011\%29/420848.html (last accessed 08 April 2020).

${ }^{14}$ https://www.uni-goettingen.de/de/anlegen+einer+publikation/415685.html (last accessed 08 April 2020).

15 https://www.uni-goettingen.de/de/benutzerhandbuch+factscience+/415687.html (last accessed 08 April 2020).

${ }^{16} \mathrm{https} / / / \mathrm{www}$.uni-goettingen.de/de/bewertungshinweise+f\%c3\%bcr+publikationen+in+factscience+ 2019/415689.html (last accessed 08 April 2020).
} 


\section{Appendix 2}

Table 9 "Performance credits" (Leistungspunkte) for scientific activities at the Technical University of Berlin (extract). Source Gläser and Laudel (2019, p.193)

\begin{tabular}{ll}
\hline Indicator & Performance credits \\
\hline Book & 16 \\
Journal publication & 8 \\
Publication in edited volume & 2 \\
Electronic publication & 2 \\
Editing a book or journal & 4 \\
Third-party funding spent & $0.4 / 1,000$ Euro $^{\text {a) }}$ \\
Leibniz Award and ERC Advanced Grant & 300 \\
\hline
\end{tabular}

${ }^{\text {a) }} \mathrm{Up}$ to the amount of 500,000 Euro. Hereafter the progression is: 0.3 performance credits for the next 500,000 Euro per 1,000 Euro, 0.2 performance credits per 1000 Euro between one and two million Euro and 0.1 performance credits per 1000 Euro for more than two million Euros

Funding Open Access funding enabled and organized by Projekt DEAL. Bundesministerium für Bildung und Forschung,M522200,Christian Schneijderberg

Open Access This article is licensed under a Creative Commons Attribution 4.0 International License, which permits use, sharing, adaptation, distribution and reproduction in any medium or format, as long as you give appropriate credit to the original author(s) and the source, provide a link to the Creative Commons licence, and indicate if changes were made. The images or other third party material in this article are included in the article's Creative Commons licence, unless indicated otherwise in a credit line to the material. If material is not included in the article's Creative Commons licence and your intended use is not permitted by statutory regulation or exceeds the permitted use, you will need to obtain permission directly from the copyright holder. To view a copy of this licence, visit http://creativecommons.org/licenses/by/4.0/.

\section{References}

Aagaard, K., Bloch, C., \& Schneider, J. W. (2015). Impacts of performance-based research funding systems: The case of the Norwegian Publication Indicator. Research Evaluation, 24(2), 106-117.

Abramo, G., D'Angelo, C. A., \& Cicero, T. (2012). What is the appropriate length of the publication period over which to assess research performance? Scientometrics, 93(3), 1005-1017.

Altbach, P. G. (Ed.). (1996). The international academic profession: portraits of fourteen countries. Princeton.

Allison, P. D., \& Long, J. S. (1990). Departmental effects on scientific productivity. American Sociological Review, 55, 469-478.

Backes-Gellner, U., \& Schlinghoff, A. (2010). Career Incentives and "Publish or Perish" in German and U.S. Universities. European Education, 42(3), 26-52.

Balsmeier, B., \& Pellens, M. (2014). Who makes, who breaks: Which scientists stay in academe? Economics Letters, 122, 229-232.

Becher, T., \& Trowler, P. R. (2001). Academic Tribes and Territories. Intellectual enquiry and the culture of disciplines (2nd ed.). Open University Press.

Bentley, P. (2012). Gender differences and factors affecting publication productivity among Australian university academics. Journal of Sociology, 48(1), 85-103.

Bloch, R., Hartl, J., O’Connell, C., \& O’Siochru, C. (2021). English and German academics' perspectives on metrics in higher education: evaluating dimensions of fairness and organisational justice. Higher Education. https://doi.org/10.1007/s10734-021-00703-w 
Bol, T., de Vaan, M., van de Rijt, A., et al. (2018). The Matthew effect in science funding. Proceedings of the National Academy of Sciences, 115(19), 4887-4890.

Bornmann, L., \& Daniel, H.-D. (2016). Count regression in informetrics. Journal of Informetrics, 10, 29-30.

Bornmann, L., Marx, W., Schier, H., Thor, A., Daniel, H.-D., et al. (2010). From black box to white box at open access journals: predictive validity of manuscript reviewing and editorial decisions at atmospheric chemistry and physics. Research Evaluation, 19(2), 105-118.

Bourdieu, P. (1975). The specifity of the scientific field and the social conditions of the progress of reason. Social Science Information, 14, 19-47.

Boyer, E. L., Altbach, P. G., Whitelaw, M. J., et al. (1994). The academic profession: an international higher perspective. Carnegie Foundation for the Advancement of Teaching.

Bracht, O. (2008). Methodenbericht der Befragung Changing Academic Profession (CAP) 2007. Unpublished Manuscript. INCHER-Kassel.

Brennan, J. (2010). Burton clark's the higher education system: academic organization in cross-national perspective. London Review of Education, 8(3), 229-237.

Butler, L. (2003a). Explaining Australia's increased share of ISI publications - the effects of a funding formula based on publication counts. Research Policy, 32(1), 143-155.

Butler, L. (2003b). Modifying publication practices in response to funding formulas. Research Evaluation, 12(1), 39-46.

Chi, P.-S. (2015). Changing publication and citation patterns in political science in Germany. Scientometrics, 105(3), 1833-1848.

Choung, J.-Y., \& Hwang, H.-R. (2013). The evolutionary patterns of knowledge production in Korea. Scientometrics, 94(2), 629-650.

Clark, B. R. (1983). The higher education system. academic organization in cross-national perspective. University of California Press.

Cole, S. (1983). The hierarchy of the sciences? American Journal of Sociology, 89, 111-139.

Cole, J. R., \& Cole, S. (1973). Social stratification in science. University of Chicago Press.

de Rijcke, S., Wouters, P. F., Rushforth, A. D., Franssen, T. P., Hammarfelt, B., et al. (2016). Evaluation practices and effects of indicator use - a literature review. Research Evaluation, 25(2), 161-169.

de Solla Price, D. J. (1963). Little science, big science. Yale University Press.

Deem, R., Mok, K. H., \& Lucas, L. (2008). transforming higher education in whose image? Exploring the concept of the 'World-Class' University in Europe and Asia. Higher Education Policy, 21(1), 83-97.

DFG - Deutsche Forschungsgemeinschaft (2013). Excellence Initiative at a Glance. Berlin.

Dyachenko, E. L. (2014). Internationalization of academic journals: Is there still a gap between social and natural sciences? Scientometrics, 101(1), 241-255.

Enders, J, \& Musselin, C. (2008). Back to the future? The Academic Professions in the 21st Century. In OECD (ed.), Higher Education to 2030 (Volume 1: Demography; pp. 125-150). Paris: OECD Publishing.

Enders, J., \& Teichler, U. (1995a). Der Hochschullehrerberuf im internationalen Vergleich. Ergebnisse einer Befragung über die wissenschaftliche Profession. Bundesministerium für Bildung, Wissenschaft, Forschung und Technologie.

Enders, J., \& Teichler, U. (1995b). Berufsbild der Lehrenden und Forschenden an Hochschulen. Ergebnisse einer Befragung des wissenschaftichen Personals an westdeutschen Hochschulen. Bundesministerium für Bildung, Wissenschaft, Forschung und Technologie.

Engels, T. C. E., Ossenblok, T. L. B., Spruyt, E. H. J., et al. (2012). Changing publication patterns in the social sciences and humanities, 2000-2009. Scientometrics, 93(2), 373-390.

Espeland, W. N., \& Sauder, M. (2007). Rankings and reactivity: how public measures recreate social worlds. American Journal of Sociology, 113, 1-40.

Espeland, W. N., \& Sauder, M. (2016). Engines of anxiety: academic rankings, reputation, and accountability. Russell Sage Foundation.

Flink, T., \& Simon, D. (2014). Erfolg in der Wissenschaft: Von der Ambivalenz klassischer Anerkennung und neuer Leistungsmessung. In D. Hänzi, H. Matthies, \& D. Simon (Eds.), Leviathan Sonderband: Vol. 29. Erfolg: Konstellationen und Paradoxien einer gesellschaftlichen Leitorientierung (1st ed., pp. 123-144). Baden-Baden: Nomos-Verl.-Ges.

Gao, Y. (2015). Constructing internationalisation in flagship universities from the policy-maker's perspective. Higher Education, 70(3), 359-373.

Gerhards, J. (2014). Deutscher Sonderweg. Drittmittel als "Ersatzmessung" der eigentlichen Leistungen. Forschung \& Lehre, 2(14), 104-105.

GFSO - German Federal Statistical Office. (2016). Promovierende in Deutschland. Wiesbaden. 
Gläser, J. (2019). How can governance change research content? Linking science policy studies to the sociology of science. In D. Simon, S. Kuhlmann, J. Stamm, \& W. Canzler (Eds.), Handbook on science and public policy (pp. 419-447). Elgar.

Gläser, J., \& Laudel, G. (2019). Die Unterkomplexität hochschulpolitischer Innovationen. In C. Schubert \& I. Schulz-Schaeffer (Eds.), Berliner Schlüssel zur Techniksoziologie (pp. 179-204). Springer.

Gralka, S., Wohlrabe, K., Bornmann, L., et al. (2019). How to measure research efficiency in higher education? Research grants vs. publication output. Journal of Higher Education Policy and Management, 41(3), 322-341.

Haddow, G., \& Hammarfelt, B. (2019). Quality, impact, and quantification: Indicators and metrics use by social scientists. Journal of the Association for Information Science and Technology, 70(1), 16-26.

Hammarfelt, B., \& de Rijcke, S. (2015). Accountability in context: effects of research evaluation systems on publication practices, disciplinary norms, and individual working routines in the faculty of Arts at Uppsala University. Research Evaluation, 24(1), 63-77.

Hardin, J. W., \& Hilbe, J. M. (2012). Generalized linear models and extensions (3rd ed.). Stata Press.

Heintz, B., \& Werron, T. (2011). Wie ist Globalisierung möglich? Zur Entstehung globaler Vergleichshorizonte am Beispiel von Wissenschaft und Sport. Kölner Zeitschrift Für Soziologie Und Sozialpsychologie, 63(3), 359-394.

Henriksen, D. (2016). The rise in co-authorship in the social sciences (1980-2013). Scientometrics, 107(2), 455-476.

Henriksen, D. (2018). What factors are associated with increasing co-authorship in the social sciences? A case study of danish economics and political science. Scientometrics, 114(3), 1395-1421.

Hicks, D. (2012). Performance-based university research funding systems. Research Policy, 41(2), 251-261.

Hicks, D., \& Wang, J. (2011). Coverage and overlap of the new social sciences and humanities journal lists. Journal of the American Society for Information Science and Technology, 62(2), 284-294.

Hopkins, A. L., Jawitz, J. W., McCarty, C., Goldman, A., Basu, N. B., et al. (2013). Disparities in publication patterns by gender, race and ethnicity based on a survey of a random sample of authors. Scientometrics, 96(2), 515-534.

Huber, M., \& Hillebrandt, M. (2019). "Pay for Promise" in higher education: the influence of NPM on resource allocation in German Universities. Historical Social Research. https://doi.org/10.12759/hsr. 44.2019.2.247-269

IECEEI - International Expert Commission for the Evaluation of the Excellence Initiative (Internationale Expertenkommission zur Evaluation der Exzellenzinitiative) 2016: Endbericht (final report). https://www.gwk-bonn.de/fileadmin/Redaktion/Dokumente/Papers/Imboden-Bericht-2016.pdf (last accessed: 07.10.2021).

Ingwersen, P., \& Larsen, B. (2014). Influence of a performance indicator on danish research production and citation impact 2000-12. Scientometrics, 101(12), 1325-1344.

Jacob, A. K., \& Teichler, U. (2011). Der Wandel des Hochschullehrerberufs im internationalen Vergleich: Ergebnisse einer Befragung in den Jahren 2007/08. Bundesministerium für Bildung und Forschung.

Jacobs, D., \& Ingwersen, P. (2000). A bibliometric study of the publication patterns in the sciences of South African Scholars 1981-96. Scientometrics, 47(1), 75-93.

Johnes, J. (2018). University rankings: what do they really show? Scientometrics, 115, 585-606.

Jungbauer-Gans, M., \& Gross, C. (2013). Determinants of success in University careers: findings from the German academic labor market. Zeitschrift Für Soziologie, 42(1), 74-92.

Kaltenbrunner, W. (2018). Situated knowledge production, international impact: changing publishing practices in a German engineering department. Minerva, 56(3), 283-303.

Karpik, L. (2011). What Is the Price of a Scientific Paper? In J. Beckert \& P. Aspers (Eds.), The worth of goods: valuation and pricing in the economy (pp. 63-85). Oxford University Press.

Kauppi, N. (2018). The global ranking game: narrowing academic excellence through numerical objectification. Studies in Higher Education, 43(10), 1750-1762.

Kim, D. H., \& Bak, H.-J. (2016). How do scientists respond to performance-based incentives? Evidence from South Korea. International Public Management Journal, 19(1), 31-52.

Klenke, D. (2012). Die Einführung der W-Besoldung: Ihre Entstehung aus zeitgeschichtlicher Perspektive. Forschung \& Lehre, 19(3), 190-193.

Kulczycki, E., Engels, T. C. E., Pölönen, J., Bruun, K., Dušková, M., Guns, R., Zuccala, A., et al. (2018). Publication patterns in the social sciences and humanities: evidence from eight European countries. Scientometrics, 116(1), 463-486.

Kwiek, M. (2018). High research productivity in vertically undifferentiated higher education systems: who are the top performers? Scientometrics, 115(1), 415-462.

Kyvik, S. (2003). Changing trends in publishing behaviour among university faculty, 1980-2000. Scientometrics, 58(1), 35-48. 
Kyvik, S., \& Aksnes, D. W. (2015). Explaining the increase in publication productivity among academic staff: a generational perspective. Studies in Higher Education, 40(8), 1438-1453.

Kyvik, S., \& Olsen, T. B. (2008). Does the aging of tenured academic staff affect the research performance of universities? Scientometrics, 76(3), 439-455.

Larivière, V., \& Sugimoto, C. R. (2019). The journal impact factor: a brief history, critique, and discussion of adverse effects. In W. Glänzel, H. F. Moed, U. Schmoch, \& M. Thelwall (Eds.), Springer handbook of science and technology indicators (pp. 3-24). Springer.

Laudel, G., \& Gläser, J. (2006). Tensions between evaluations and communication practices. Journal of Higher Education Policy and Management, 28(3), 289-295.

Leahey, E. (2007). Not by productivity alone: how visibility and specialization contribute to academic earnings. American Sociological Review, 72(4), 533-561.

Long, J. S., \& Freese, J. (2014). Regression models for categorical dependent variables using Stata (3rd ed.). Stata Press.

Lotka, A. (1926). The frequency distribution of scientific productivity. Journal of the Washington Academy of Sciences, 16(12), 317-324.

Lutter, M., \& Schröder, M. (2016). Who becomes a tenured professor, and why? Panel data evidence from German sociology, 1980-2013. Research Policy, 45, 999-1013.

Lynn, F. B., Podolny, J. M., Tao, L., et al. (2009). A sociological (de)construction of the relationship between status and quality. American Journal of Sociology, 115(3), 755-804.

Lyu, Q., Pu, Q., \& Zhang, J. (2017). Bibliometric analysis of scientific publications in endocrinology and metabolism from China, Japan, and South Korea. Scientometrics, 110, 105-112.

Marginson, S., \& Considine, M. (2000). The Enterprise University. Power, Governance and Reinvention in Australia. Cambridge University Press.

Mathies, C., Kivistö, J., Birnbaum, M., et al. (2020). Following the money? Performance-based funding and the changing publication patterns of Finnish academics. Higher Education, 79(1), 21-37.

McClelland, C. E. (1990). Escape from freedom? reflections on german professionalization, 1870-1933. In R. Torstendahl \& M. Burrage (Eds.), The formation of professions: knowledge, state and strategy (pp. 97-113). Sage.

Mergele, L., \& Winkelmayer, F. (2021). The relevance of the German excellence initiative for inequality in University funding. Higher Education Policy. https://doi.org/10.1057/s41307-021-00233-1

Merton, R. K. (1968). The Matthew effect in science: the reward and communication systems of science are considered. Science, 159, 56-63.

Michels, C., \& Schmoch, U. (2014). Impact of bibliometric studies on the publication behaviour of authors. Scientometrics, 98(1), 369-385.

Moed, H. F. (2008). UK research assessment exercises: informed judgments on research quality or quantity? Scientometrics, 74(1), 153-161.

Mohrman, K., Ma, W., Baker, D., et al. (2008). The research university in transition: the emergent global model. Higher Education Policy, 21, 5-27.

Münch, R. (2014). Academic capitalism: universities in the global struggle for excellence. Routledge.

Orr, D., Jaeger, M., Schwarzenberger, A., et al. (2007). Performance-based funding as an instrument of competition in German higher education. Journal of Higher Education Policy and Management, 29(1), 3-23.

Ossenblok, T. L. B., Verleysen, F. T., Engels, T. C. E., et al. (2014). Coauthorship of journal articles and book chapters in the social sciences and humanities (2000-2010). Journal of the Association for Information Science and Technology, 65(5), 882-897.

Osuna, C., Cruz-Castro, L., Sanz-Menéndez, L., et al. (2011). Overturning some assumptions about the effects of evaluation systems on publication performance. Scientometrics, 86, 575-592.

Papke, L. E., \& Wooldridge, J. M. (1996). Econometric methods for fractional response variables with an application to $401(\mathrm{k})$ plan participation rates. Journal of Applied Econometrics, 11, 619-632.

Park, H. W., Yoon, J., Leydesdorff, L., et al. (2016). The normalization of co-authorship networks in the bibliometric evaluation: the government stimulation programs of China and Korea. Scientometrics, 109, 1017-1036.

Pusser, B. (2008). The state, the market and the institutional estate: Revisiting contemporary authority relations in higher education. In J. Smart (Ed.), Higher education: handbook of theory and research (Vol. 23, pp. 105-139). New York: Agathon.

Puuska, H.-M. (2010). Effects of scholar's gender and professional position on publishing productivity in different publication types. Analysis of a finnish University. Scientometrics, 82(2), 419-437.

Puuska, H.-M. (2014). Scholarly publishing patterns in Finland: a comparison of disciplinary groups. Academic dissertation. Tampere University Press.

Rabe-Hesketh, S., \& Skrondal, A. (2012). Multilevel and longitudinal modeling using stata (3rd ed.). A Stata Press Publication. 
Saam, N. J., \& Reiter, L. (1999). Lotka's law reconsidered: the evolution of publication and citation distributions in scientific fields. Scientometrics, 44(2), 135-155.

Scott, W. R. (2005). Evolving professions: an institutional field approach. In T. Klatetzki \& V. Tacke (Eds.), Organisation und profession (pp. 119-142). VS Verlag.

Schimank, U. (2005). 'New public management' and the academic profession: reflections on the German situation. Minerva, 43(4), 361-376.

Schimank, U. (2010). Reputation statt Wahrheit: Verdrängt der Nebencode den code? Soziale Systeme, 16(2), 233-242. https://doi.org/10.1515/sosys-2010-0204

Schneijderberg, C., \& Götze, N. (2020). Organisierte, metrifizierte und exzellente Wissenschaftler*innen. Veränderungen der Arbeits- und Beschäftigungsbedingungen an Fachhochschulen und Universitäten von 1992 über 2007 bis 2018. International Centre for Higher Education Research. Kassel. https://doi. org/10.5281/zenodo.3949756.

Schneijderberg, C., Götze, N., Jones, G. A., Bilyalov, D., Panova, A., Stephenson, G. K., \& Yudkevich, M. (2021). Does vertical University stratification foster or hinder academics' societal engagement? Findings from Canada, Germany, Kazakhstan, and Russia. Higher Education Policy. https://doi.org/10. 1057/s41307-020-00219-5

Schubert, T, Frietsch, R., Rothengatter, O. (2017). An analysis of the Excellence Initiative and its effects on the funded universities. Studien zum deutschen Innovationssystem Nr. 11-2017. Karlsruhe: Fraunhofer Institute for Systems and Innovation Research ISI.

Selten, F., Neylon, C., Huang, C.-K., Groth, P., et al. (2020). A longitudinal analysis of university rankings. Quantitative Science Studies, 1(3), 1109-1135.

Shin, J. C. (2009). Building world-class research University: the brain Korea 21 project. Higher Education, 58(5), 669-688.

Shin, J. C., \& Cummings, W. K. (2010). Multilevel analysis of academic publishing across disciplines: research preference, collaboration, and time on research. Scientometrics, 85(2), 581-594.

Shin, J. C., \& Lee, S. J. (2015). Evolution of research universities as a national research system in Korea: accomplishments and challenges. Higher Education, 70(2), 187-202.

Shin, J. C., Jung, H., \& Lee, S. J. (2021). Performance-based research funding and its impacts on Academics' publication patterns in South Korea. Higher Education Policy. https://doi.org/10.1057/ s41307-021-00245-X

Shin, J. C., Kim, H., Park, H. Y., Shim, H. K., et al. (2009). Analysis on the factors of budget allocation to universities: evaluation-based funding mechanism. The Journal of Economics and Finance of Education, 18(4), 59-87.

Sivertsen, G. (2016). Patterns of internationalization and criteria for research assessment in the social sciences and humanities. Scientometrics, 107, 357-368.

Snijders, T. A. B., \& Bosker, R. J. (2012). Multilevel analysis: An introduction to basic and advanced multilevel modeling (2nd ed.). Sage.

Stata Corp (2015). Stata statistical software: release 14. College Station: StataCorp LP.

Stichweh, R. (1994): Wissenschaft, Universität, Profession. Frankfurt a. M.: Suhrkamp.

Stroebe, W. (2010). The graying of academia: will it reduce scientific productivity? The American Psychologist, 65(7), 660-673.

Teichler, U., Arimoto, A., Cummings, W. K., et al. (2013). The changing academic profession. Major findings of a comparative survey. Springer.

van Dalen, H. P., \& Henkens, K. (2012). Intended and unintended consequences of a publish-or-perish culture: a worldwide survey. Journal of the American Society for Information Science and Technology, 63(7), 1282-1293.

Vatin, F. (2013). Valuation as evaluating and valorizing. Valuation Studies, 1(1), 31-50.

Volkmann, U., Schimank, U., Rost, M., et al. (2014). Two Worlds of academic publishing: chemistry and german sociology in comparison. Minerva, 52(2), 187-212.

Vormbusch, U. (2012). Die Herrschaft der Zahlen Zur Kalkulation des Sozialen in der kapitalistischen Moderne. New York: Frankfurt a. M.

Whitley, R. (2007). Changing governance of the public sciences. In R. Whitley \& J. Gläser (Eds.), The changing governance of the sciences. Sociology of the sciences yearbook (pp. 3-27). Dordrecht: Springer.

Wilkesmann, U., \& Schmid, C. J. (2012). The impacts of new governance on teaching at German universities. Findings from a national survey in Germany. Higher Education, 63, 33-52.

Woelert, P., \& McKenzie, L. (2018). Follow the money? How Australian universities replicate national performance-based funding mechanisms. Research Evaluation, 27(3), 184-195.

Zacharewicz, T., Lepori, B., Reale, E., Jonkers, K., et al. (2019). Performance-based research funding in EU member States - a comparative assessment. Science and Public Policy, 46(1), 105-115. 